\title{
An analysis and Design of An Automated Dashboard technologies for developing web based applications - BHAIKENOTES
}

\author{
Vivek Singh $^{\mathrm{a}}$, Avanish Pratap Singh ${ }^{\mathrm{b}}$, Yashu Sharma ${ }^{\mathrm{c}}$, Damodharan. ${ }^{\mathrm{d}}$ \\ a, b, c Students, Department of Computer Science Galgotias University Greater Noida, UP India \\ ${ }^{\mathrm{d}}$ Assistant Professor,Department of Computer Science Galgotias University Greater Noida, UP India \\ avivek.singh10723@gmail.com, baps10071999@gmail.com, \\ cyashusharma@gmail.com ${ }^{\mathrm{d}}$ amodharan@galgotiasuniversity.edu.in
}

Article History: Received: 10 November 2020; Revised 12 January 2021 Accepted: 27 January 2021; Published online: 5 April 2021

\begin{abstract}
Dashboard are relied upon to improve dynamic by enhancing cognizance and gaining by human perceptual capacities. Subsequently, premium in dashboards has expanded as of late, which is additionally obvious from the expansion of dashboard arrangement suppliers on the lookout. Regardless of dashboards' fame, little is thought about the degree of their viability, for example what sorts of dashboards turn out best for various clients or undertakings. In this paper, we direct a complete multidisciplinary writing survey with a plan to recognize the basic issues associations may have to consider while actualizing dashboards. Dashboards are probably going to succeed and take care of the issues of introduction organization and data load when certain perception standards and highlights are available (for example high information ink proportion and drill down highlights). We suggest that dashboards accompany some degree of adaptability, for example permitting clients to switch between elective introduction designs. Additionally, some hypothesis driven direction through pop-ups and alerts can assist clients with choosing a fitting introduction design.In this dashboard user can get notes of all subjects as well as all the stuff which help him grabbing a good job and also provide internships notification to users. The machine learning helps them what they require and the best result will come for them to support them.This also give the option of chatting so they can chat among the other users for any help.This also use cloud for saving their data and for faster access.So, this dashboard use web development, cloud and machine-learning and the languages for this are mainly Html,css,Bootstrap,Javascript and Php and some sqlUsers will provide the notification of many events like exam and hackathon through this dashboard.
\end{abstract}

Keywords: Navigation, Impressive, Effective, Development

\section{Introduction}

A dashboard was initially characterized as a key accessory in a vehicle, as per the Oxford word reference. Then, an advanced dashboard is characterized as "a visual presentation of the main data expected to accomplish at least one destinations".Dashboard configuration has incompletely been considered as specialized devices among information and information. Numerous practices in different spaces can add to thegeospatial dashboard plan. a superior planned visualperception strategy assumes a significant part in adequately showing information. The Gestalt brain science strategy and composed numerous perspectives (CMV) are the fundamental basic and intuitive techniques utilized in data representation plan. In this dashboard user can get notes of all subjects as well as all the stuff which help him grabbing a good job.

We provide internships notification to users. Highly automated dashboard use the machine learning in helping students what they require and the best result will come for them to fetch the required result.Hoghly automated dashboard also give the option of chatting so they can chat among the other users for any help.Highly automated dashboard also use cloud for saving their data and for faster access. The service has website supporting for the Andriod and IOS Devices of any screen size. Highly automated dashboard also makes a profile of each user and satisfy them according to their needs.

For A dashboard Development resembles house working, before house building measure, we get some information about arrangement, building grant, supervise a review of land and permit from city. Everything should need to find in the site improvement prerequisite, planning, documentation, proper worker also, programming language and so on . Most vital things for a site is choosing a programming language. Generally website composition utilizing HTML also, CSS. For web planning redundant elevated level information on HTML.

We can say highlights like as website page organizing, planning, page format strategies, designs, mixed media, pictures and elements of multipage site should incorporate. In the wake of programming language to see the design of website page should a test worker. The purpose for is engineer is utilizing programming language, if 
will be the master of language yet as yet running regularly these mix-ups can't be found, there is a need to execute worker side codding to see the see by a test worker.

\section{Literature Review}

Our project is used to upload notes and other study stuffs easily through one platform. We Hosted it on InfinityFree Web Hosting so it is very easy to use and accessible to others. In this we have used the technology of web development.

InfinityFree provides Free web Hosting with Unlimited Disk Space, Unlimited Bandwidth, and various options with database and NO forced ads with $100 \%$ uptime. So it helps our project with full accessibility and availability and ease of use for our users and for us as well. This makes it cost effective along with reducing the workload of maintaining the hosting cost and storage problems. We have designed the main page and navigation that helps to move from one page to another for fulfill the given requirements of the user. We basically created all pages responsive as well as attractive.

\section{Existing \& proposed system:}

Students makes notes from different platforms which was time taking. All study material not found at the same portal.

Students do no find placement materials as well as good material at the same dashboard.Students takes so much time to make the notes.Students have not multiple option in the same dashboard like chatting,rating,and notification.

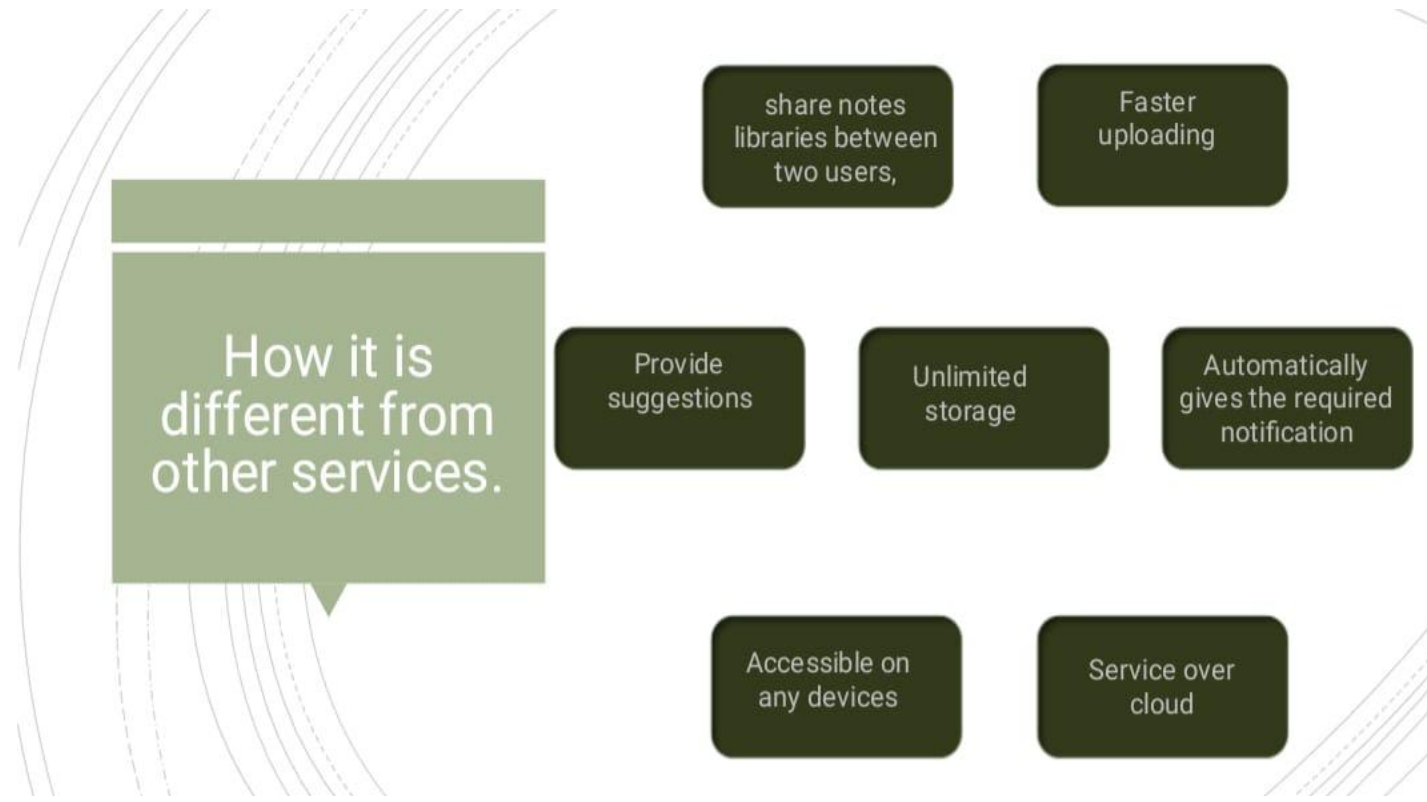

Fig1: How it is different from other services.

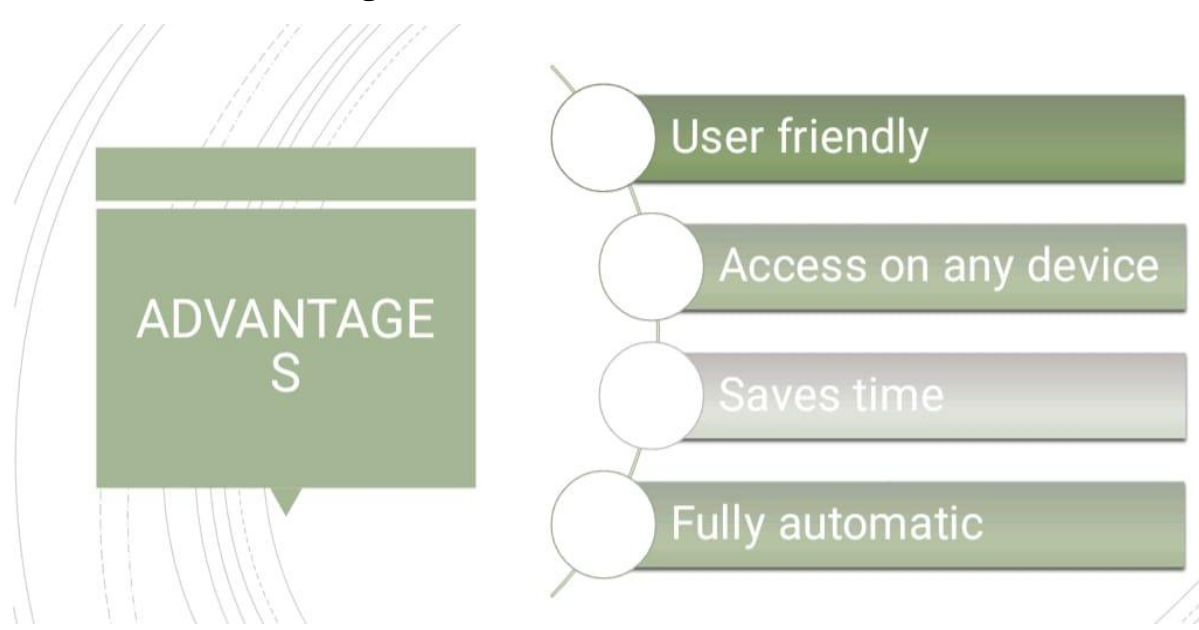

Fig2:Advantages of this system. 
This dashboard provides the all services which cannot provided by existing dashboard.

\section{Implementation}

We implemented this dashboard using web development. We hosted it on InfinityFree. In it we store the notes as per events and time. We use PHP code that fetch notes from folder stored on Hosting platform storage then display them in designed format. Different categories of notes are given in navigation bar where we can move into that category page and look the notes of particular branch. In it we created and implemented different web pages say homepage, contact us, about us and then different subpages for different categories. A. Tools Used for Implementation

For Frontend:

- HTML used to build the structure of pages and to give headings, paragraphs and links.

-CSS used for describing the presentation of web pages including colors, layout, and fonts.

- BOOTSTRAP used for designing the web pages.

- JQUERY adds more features to web pages.

For Backend:

- PHP is used to fetch the photos from folder stored on hosted platform storage.

- JS used on both client side and server side that allows you to make web page interactive and more responsive.

- ajax used in backend of page.

\section{Use Case diagram}

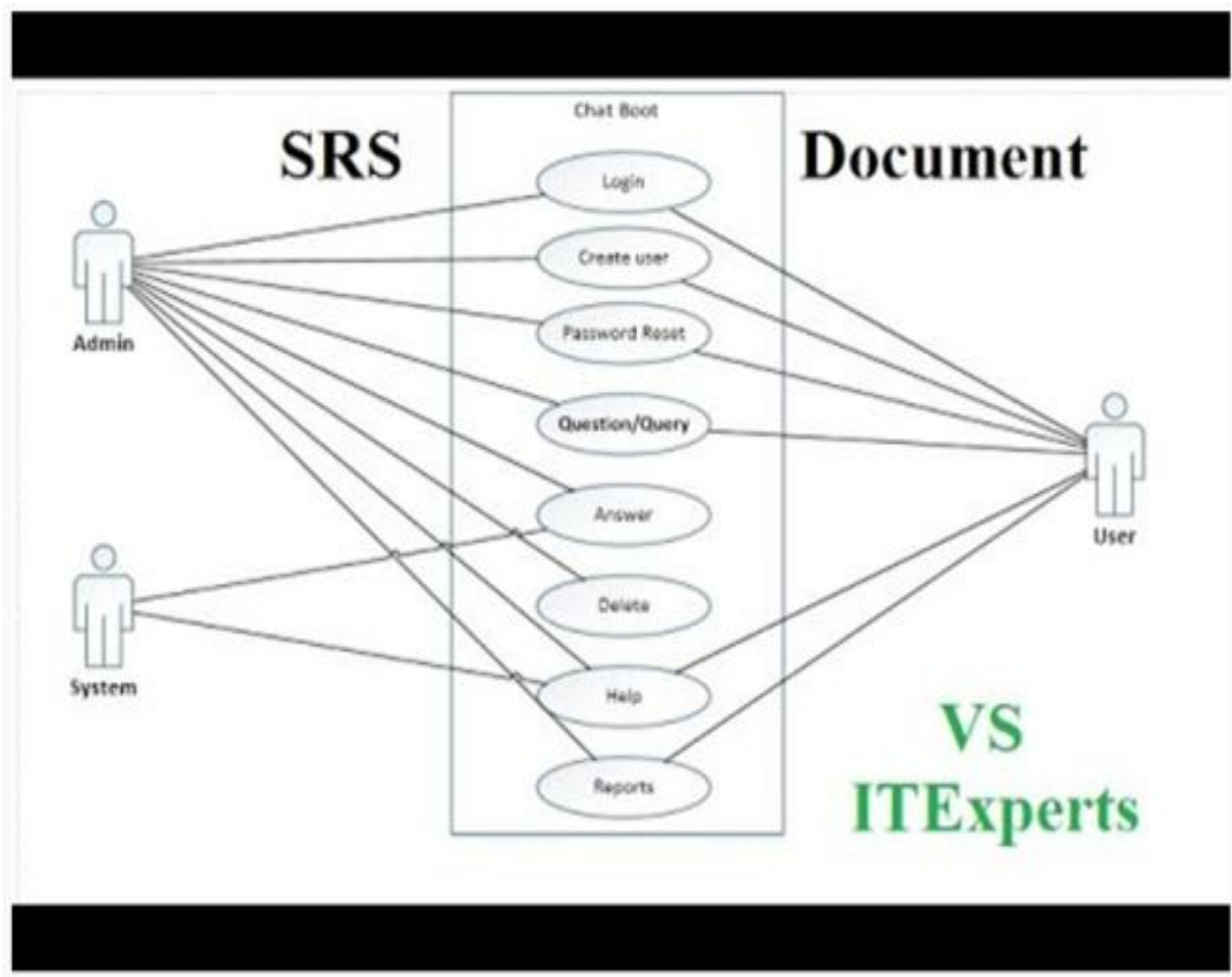

Fig 3:Use Case diagram

Tools used for implementation 
- $\quad$ PHP My ADMIN

- $\quad$ SUBLIME TEXT

- $\quad$ MY SQL IN PHP ADMIN

- And some basic editors for frontend part.

We have designed the main page and how to move from one page to another for fulfill the givenrequirements of theuser. We basically created some pages which are responsive as well as attractive. We use for making the pages:

\section{HTML,CSS \\ BOOTSTRAP}

JavaScript

For Data base we use My sql for saving notes and use some php.

5. Methods

\section{Some of the methods for creation of dashboard are:}

1. Define Your Dashboard Audience And Objective.

2. Select The Right Chart Type For Your Data.

3. Don't Forget About Color Theory.

4. Build a Balanced Perspective

\section{Result}

The main purpose behind our last year project was to give a stage to the understudies of various branches and groups of the school to download their notes, ppts and documents of the relative multitude of subjects they have in their prospectus, and as to share the best notes of these subjects everybody so cap they can concentrate from those simple and reasonable notes and score passing marks and gpa in school. It likewise assisted us with having the experience of working in a group and a work space starting at an organization. This last year project have mostly revealed two beneficial outcomes. To begin with, we are more ready for the work life as issue solvers, since they know about a cycle for deliberately taking care of issues utilizing point, goals, and techniques. By applying this cycle, understudies that have begun to work will in general take care of issues in a more efficient and complete manner (and frequently speedier) than understudies that have not been presented to a comparative interaction. Having worked thusly, organizations can allow understudies to take on more qualified and testing undertakings before in their professions. This obviously influences the understudy's headway and self-awareness in a positive manner. The subsequent beneficial outcome detailed by organizations concerns, the understudy's capacity to compose and introduce reports. Every understudy composes a report of around 40-60 pages that explains on what the issue is, the reason it is an issue, the issue's hypothetical setting, different methodologies for how it very well may be tackled, how it was addressed, how it was examined, and ends that can be drawn. Having composed and introduced such a report additionally makes it simpler for understudies to see how to compose and introduce great venture reports inside an organization.

\section{Conclusion}

Such dashboards help to outline key figures on a screen loaded with data and give visual, utilitarian, or potentially intelligent logical highlights to deal with lumps of data viably. Likewise, these devices can likewise help guarantee that operational leaders in associations are not overpowered by the torrential slide of information when attempting to utilize data adequately.

The test for contemporary associations and related examination is, along these lines, to make the gathered information more important to operational chiefs. Dashboards and their basic highlights have become a fundamental way to deal with tending to this test.

In this paper we have prepared the web application using web development technology to give a platform to share notes, study stuffs and can chat with others.

\section{References}

A review of dashboards in performance management: implications for design and research.

Al-Ghourabi, A. (2006). A comparison of web development technologies: WebObjects vs. ASP .NET. Rochester institute of technology. 
I.T Project Analysis, Design \& Implementation Student Portal System Francis Keke B00030104 Daniel Nistor B00032909 Department of Business School of Business \& Humanities Institute of Technology, Blanchardstown Dublin 15. [Word Limit for Assignment: None Actual word count: 24646] Bachelor of Business (Hons) in Information Technology I.T Project: Implementation 01/05/2014

DimaJalal,Mutaz M. Al-Debei (2012) . Portals and Task Innovation: A Theoretical Framework Founded on Business Intelligence Thinking, 1208.0892.pd

ZhilinYanga, ShaohanCaib, ZhengZhouc, Nan Zhoua (2004). Development and validation of an instrument to measure user perceived service quality of information presenting Web portals, Information \& Management 42 (2005) 575-589

Design of an academic web portal providing e-facilities.

Bozzon, A. ,. (2006). Conceptual modeling and code generation for rich internet applications.International conference on Web engineering.

Cecchet, E. C. (2003). A Comparison of Software Architectures for E-business Applications. Middleware Conference. Rio de Janeiro, Brazil 